\title{
Free-Surface Flow Over River Bottom Sill: Experimental and Numerical Study
}

\author{
Evangelia D. Farsirotou ${ }^{1} \cdot$ Spiridon I. Kotsopoulos ${ }^{1}$
}

Received: 29 January 2015 / Accepted: 22 July 2015 /Published online: 30 August 2015

(C) Springer International Publishing Switzerland 2015

\begin{abstract}
This paper reports on a laboratory study that was performed in an experimental model in the Technological Educational Institute of Thessaly. The current research work examines the water surface profile variation in abruptly altered open channel topography. The objective is to investigate the effects of river bottom sills on flow depth for river control protection against floods. A rectangular bottom sill with one edge rounded was placed on the bottom of a rectangular, horizontal, laboratory open flume and measurements were performed of free-surface flow depth over the bottom sill, under steady flow conditions, for different inflow discharges. Moreover, the HEC-RAS simulation model was used to numerically simulate the water surface variation over the rectangular bottom sill, under steady flow conditions. A mixed flow regime simulation was performed in order to validate the transition from subcritical to supercritical flow conditions. The computed flow depth variation over the rectangular bottom sill was compared with the obtained experimental measurements in order to demonstrate the accuracy of the performed measurements. The presented experimental data may be used to assist in the development of new and the verification and refinement of existing river hydraulic numerical simulation models, particularly those which use non-hydrostatic pressure distribution.
\end{abstract}

Keywords Rectangular bottom sill - Water surface variation - Experimental measurements · Numerical simulation

\section{Introduction}

In recent years preventive measures which aim at reducing flood events in rivers are of paramount importance. From the engineering view point, the accurate quantitative estimation of free-surface flow variation in open channels is necessary for the prevention of severe

Evangelia D. Farsirotou

efars@teilar.gr

1 Department of Civil Engineering T.E., Technological Educational Institute of Thessaly, Larissa 411 10 , Greece 
environmental problems. The placement of different local bottom sills along alluvial channels may produce abrupt changes and variation of the flow pattern over the sill: underestimation of flow depth may lead to local flooding while overestimation may increase construction cost. The construction of local bottom sills on natural river beds is very common as they change initial bed slope and their presence accentuates the bottom slope effect. In river control engineering works local sills are usual hydraulic structures that act as obstacles to the flow and provide abrupt free-surface flow pattern variation. An accurate prediction of hydraulic characteristics as a function of inflow discharge and construction geometry is necessary for a safe river design.

Free-surface flow variation has been the subject of many studies in the past. Bahallamudi and Chaudhry (1992) studied numerically water surface variation in open-channel transitions and Meselhe et al. (1997) developed an implicit numerical scheme for simulating transcritical flows of particular interest. Bravo and Zheng (2000) studied numerically and experimentally flow characteristics over a rectangular bottom step with rounded edges. Zerihum and Fenton (2006) and Liang et al. (2007) numerically simulated transcritical flows at short length transitions in open channel flow structures. The effect of abrupt channel bottom variations in unsteady flow was investigated by Ozmen-Cagatay and Kocaman (2011) using a trapezoidal bottom sill. Hamidifar and Omid (2011) have performed experimental measurements and analyzed the effect of a broad crested sill on forming a controlled hydraulic jump in a triangular channel. Demetriou and Retsinis (2013) performed experimental measurements of the length of a steady-weak hydraulic jump near a thin sill in an inclined channel. Farsirotou et al. (2014) have performed laboratory measurements and investigated the effect of a triangular bottom sill on water depth variation.

This research work focuses on the effect of abrupt changes in river topography on freesurface flow variation using a rectangular bottom sill. Laboratory experiments were carried out and water depth measurements over the obstacle produce a reliable database intended as support in the development of new and the refinement of existing numerical models for simulating non-uniform flows in rivers, particularly those using non-hydrostatic pressure distribution. A one dimensional hydraulic model simulation containing the rectangular bottom sill was performed and numerical results of water surface variation above the sill were compared with current experimental measurements.

\section{Experimental Laboratory Equipment}

\subsection{Testing Flume Description and Procedures}

Laboratory studies were conducted in an existing setup in the Hydraulic Laboratory of the Civil Engineering T.E. Larissa Department of the Technological Educational Institute of Thessaly. A smooth, prismatic channel, of rectangular cross-section, $6.0 \mathrm{~m} \mathrm{long}, 0.076 \mathrm{~m}$ wide and $0.25 \mathrm{~m}$ deep was used for the experiments. The flume walls were made of $10 \mathrm{~mm}$ thick plexiglas. The experiments were performed over two different bottom sill geometries made of waterproof wood. First, a triangular symmetrical bottom sill was used (Farsirotou et al. 2014), and as a second case, a rectangular symmetrical bottom sill with one edge rounded was placed on the bottom of the flume with height equal to $0.10 \mathrm{~m}$ and a flat crown equal to $0.32 \mathrm{~m}$. The bottom sill was located at a distance of $1.90 \mathrm{~m}$ from the channel inlet to achieve uniform fully developed flow before the sill. All experimental flow depth measurements were 
conducted at the center line of the channel along the main flow direction and were recorded using a point gauge introducing an optical error of $\sim 0.1 \mathrm{~mm}$. The bottom slopes of the tested flume, in longitudinal and transverse directions, were set equal to zero.

The experimental laboratory equipment with the triangular bottom sill is presented in Fig. 1a (Farsirotou et al. 2014). The inflow discharge from the pump was measured using a flowmeter connected to the channel (Fig. 1a). Due to fluctuations, the time average inflow discharge in each experimental test was computed and used. Figure $1 \mathrm{~b}$ shows a schematic view of the rectangular bottom sill with the free-surface flow variation over the obstacle. Table 1 indicates the geometric coordinates of the rectangular bottom sill which are the cross-sections where flow depth measurements were obtained.

\subsection{Experimental Results}

Experimental measurements of free-surface flow variation, over the rectangular bottom sill, under equilibrium flow conditions, were obtained at the center line of the channel along the main flow direction. Water inflow discharges values were set equal to: $\mathrm{Q}_{1}=0.10 \mathrm{~L} / \mathrm{s}, \mathrm{Q}_{2}=$ $0.20 \mathrm{~L} / \mathrm{s}, \mathrm{Q}_{3}=0.30 \mathrm{~L} / \mathrm{s}, \mathrm{Q}_{4}=0.40 \mathrm{~L} / \mathrm{s}, \mathrm{Q}_{5}=0.50 \mathrm{~L} / \mathrm{s}, \mathrm{Q}_{6}=0.60 \mathrm{~L} / \mathrm{s}, \mathrm{Q}_{7}=0.70 \mathrm{~L} / \mathrm{s}, \mathrm{Q}_{8}=0.80 \mathrm{~L} / \mathrm{s}$ and $\mathrm{Q}_{9}=0.91 \mathrm{~L} / \mathrm{s}$. The water surface measurements, $\mathrm{H}(\mathrm{m})$, over the rectangular bottom sill, under steady flow conditions, for all the aforementioned inflow discharges are shown in Fig. 2. Laboratory flow conditions, experimental Froude number variation, at the upstream and at the downstream edge of the rectangular bottom sill, Reynolds numbers and average flow velocities at the upstream edge of the sill, for each inflow discharge are given in Table 2.

(a)

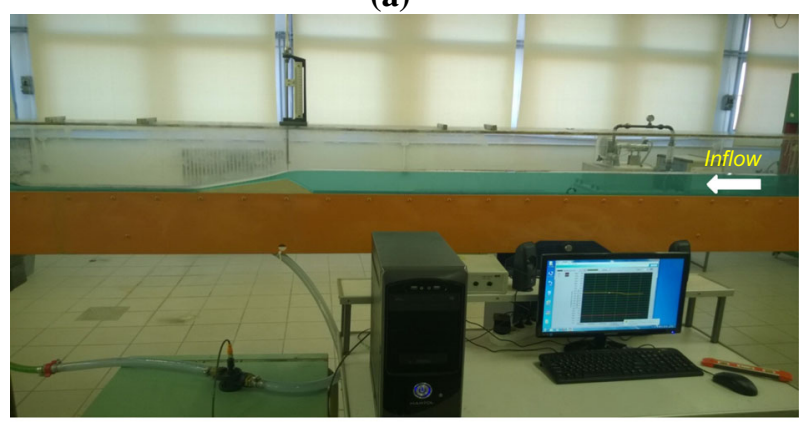

(b)

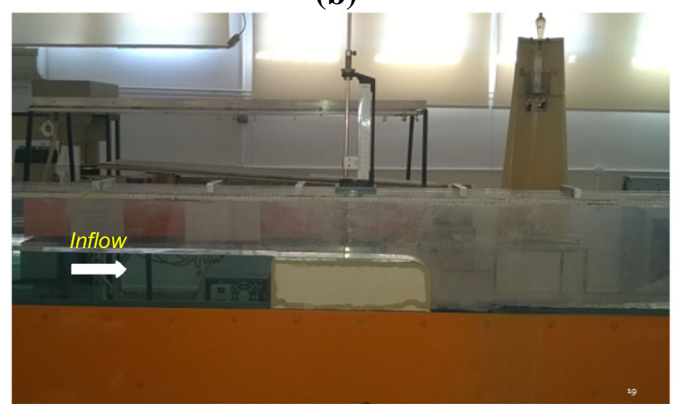

Fig. 1 a Experimental setup and laboratory equipment, $\mathbf{b}$ Schematic view of the rectangular bottom sill and freesurface flow presentation 
Table 1 Geometrical coordinates of the rectangular bottom sill

\begin{tabular}{llllll}
\hline $\mathrm{a} / \mathrm{a}$ & $\begin{array}{l}\text { Axial distance } \\
\mathrm{x}(\mathrm{m})\end{array}$ & Rectangular sill height $\mathrm{z}(\mathrm{m})$ & $\begin{array}{l}\mathrm{a} / \mathrm{a} \\
\text { Axial distance } \\
\mathrm{x}(\mathrm{m})\end{array}$ & Rectangular sill height $\mathrm{z}(\mathrm{m})$ \\
\hline 1 & 0.02 & 0.10 & 12 & 0.24 & 0.10 \\
2 & 0.04 & 0.10 & 13 & 0.26 & 0.10 \\
3 & 0.06 & 0.10 & 14 & 0.28 & 0.10 \\
4 & 0.08 & 0.10 & 15 & 0.30 & 0.10 \\
5 & 0.10 & 0.10 & 16 & 0.31 & 0.10 \\
6 & 0.12 & 0.10 & 17 & 0.32 & 0.0996 \\
7 & 0.14 & 0.10 & 18 & 0.33 & 0.0952 \\
8 & 0.16 & 0.10 & 19 & 0.34 & 0.0883 \\
9 & 0.18 & 0.10 & 20 & 0.345 & 0.0806 \\
10 & 0.20 & 0.10 & 21 & 0.35 & 0.00 \\
11 & 0.22 & 0.10 & & & \\
\hline
\end{tabular}

\section{One-Dimensional Numerical Simulation}

A one-dimensional numerical simulation of non-uniform water surface profile variation over the rectangular bottom sill, along the flow direction, was also performed under steady flow conditions. The Hydrologic Engineering Center's River Analysis System (HEC-RAS) model was used which is based on the application of the momentum equation (Farsirotou et al. 2002; US Army Corps of Engineers 2010).

The momentum equation was applied to simulate rapidly varying flow conditions and transition from subcritical to supercritical flow in the vicinity of the bottom sill. Water surface profiles were computed from one cross section to the next by solving the momentum equation between two adjacent cross sections 1 and 2, as follows:

$$
\frac{Q_{2}^{2} \beta_{2}}{g A_{2}}+A_{2} Y_{2}+\left(\left(\frac{A_{1}+A_{2}}{2}\right)\right) L S_{0}=\frac{Q_{1}^{2} \beta_{1}}{g A_{1}}+A_{1} Y_{1}+\left(\left(\frac{A_{1}+A_{2}}{2}\right)\right) L S_{f}
$$

where Q $\left(\mathrm{m}^{3} / \mathrm{s}\right)$ is the discharge, $\beta$ is a momentum coefficient that accounts for a varying velocity distribution in irregular channels and for regular channels is equal to one, $\mathrm{A}\left(\mathrm{m}^{2}\right)$ is the wetted area of the cross section, $\mathrm{Y}(\mathrm{m})$ is the water depth, $\mathrm{L}(\mathrm{m})$ is the distance between cross sections 1 and 2 along the flow direction, $g$ is the acceleration due to gravity $\left(\mathrm{m} / \mathrm{s}^{2}\right), \mathrm{S}_{0}$ is the slope of the channel, and $\mathrm{S}_{\mathrm{f}}$ is the slope of the energy grade line (friction slope). The friction slope at each cross-section is computed from Manning's equation as:

$$
\begin{aligned}
& S_{f}=\left(\frac{Q}{K}\right)^{2} \\
& K=\frac{1}{n} A R^{2 / 3}
\end{aligned}
$$

where $\mathrm{K}$ is the conveyance of a cross-section, $\mathrm{n}$ is the Manning's roughness coefficient, and $\mathrm{R}$ is the hydraulic radius of a cross-section. 

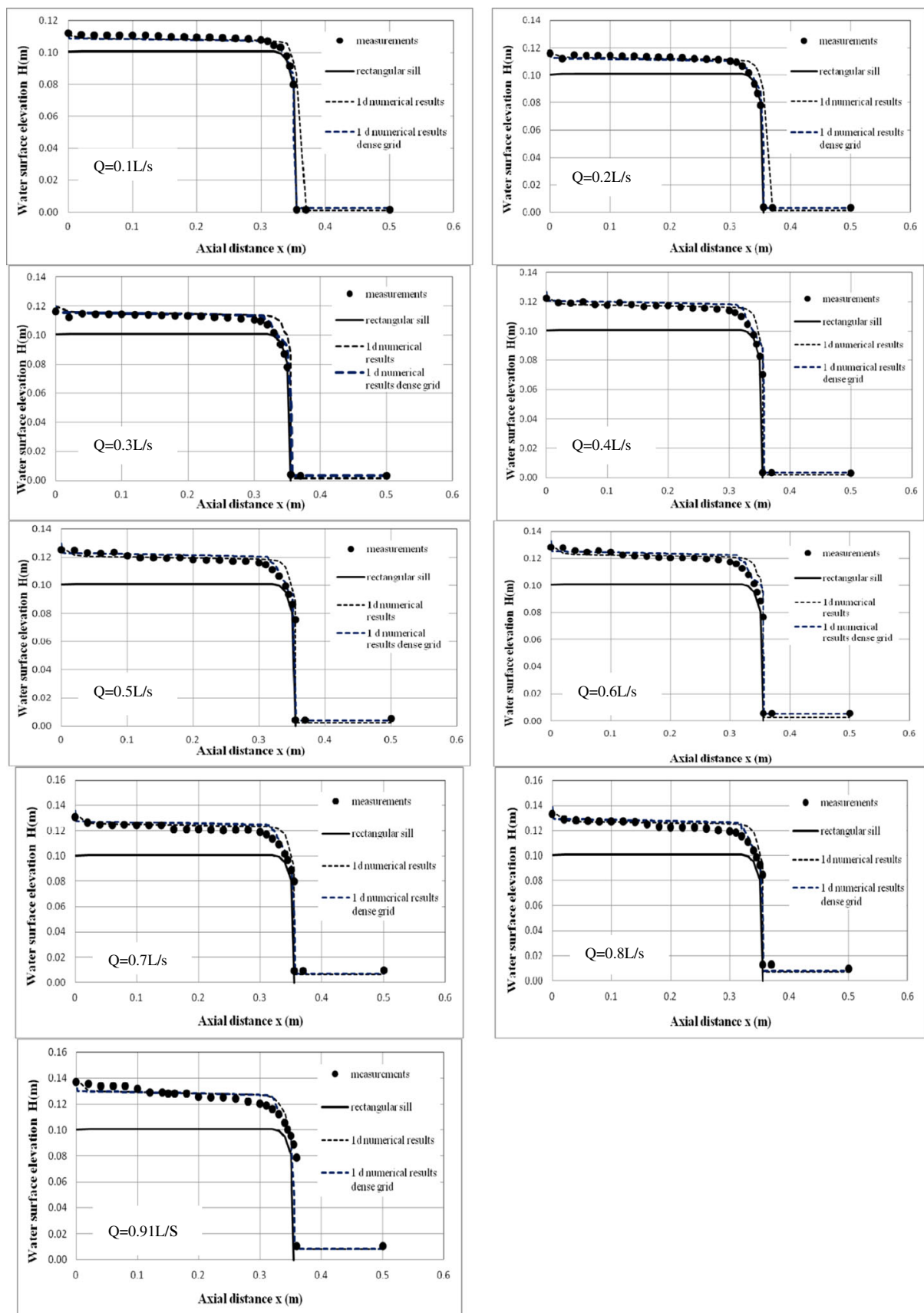

Fig. 2 Comparison between numerical and experimental free-surface variation over the rectangular bottom sill, at different inflow discharges

Initially, spatial steps $\Delta x$ of 0.02 and 0.005 were used along the flow direction in the region of the sill, and in order to achieve a more accurate simulation, a spatial step $\Delta \mathrm{x}$ of 0.002 was 
Table 2 Laboratory hydraulic conditions

\begin{tabular}{llllll}
\hline a/a & $\begin{array}{l}\text { Water inflow } \\
\text { discharge } \\
\mathrm{Q}(\mathrm{L} / \mathrm{s})\end{array}$ & $\begin{array}{l}\text { Upstream } \\
\text { Froude number }\end{array}$ & $\begin{array}{l}\text { Downstream } \\
\text { Froude number }\end{array}$ & $\begin{array}{l}\text { Upstream } \\
\text { Reynolds number }\end{array}$ & $\begin{array}{l}\text { Upstream } \\
\text { Average velocity } \\
(\mathrm{m} / \mathrm{s})\end{array}$ \\
\hline 1 & 0.10 & 0.3515 & 8.384 & $1.375610^{-9}$ & 0.1185 \\
2 & 0.20 & 0.4615 & 3.588 & $2.843510^{-9}$ & 0.1811 \\
3 & 0.30 & 0.5095 & 4.672 & $3.983310^{-9}$ & 0.2164 \\
4 & 0.40 & 0.5192 & 5.574 & $5.270410^{-9}$ & 0.2406 \\
5 & 0.50 & 0.5383 & 5.950 & $6.585110^{-9}$ & 0.2655 \\
6 & 0.60 & 0.5465 & 6.210 & $7.934210^{-9}$ & 0.2854 \\
7 & 0.70 & 0.5544 & 3.347 & $9.250210^{-9}$ & 0.3033 \\
8 & 0.80 & 0.5638 & 3.468 & $1.053910^{-8}$ & 0.3203 \\
9 & 0.91 & 0.5690 & 3.605 & $1.197810^{-8}$ & 0.3364 \\
\hline
\end{tabular}

then used. The Manning roughness coefficient was estimated to be equal to 0.01. A transcritical flow regime simulation, under steady flow conditions, was performed in order to simulate the transition from subcritical to supercritical flow conditions, over the sill, for every inflow discharge. Both updtream and downstream boundary conditions were applied in the numerical simulation model.

\section{Computational Results}

In Fig. 2 the computed numerical results of free-surface profiles, over the obstacle, under steady flow conditions, at different inflow discharges, are compared with experimental results. Moreover, as the numerical model does not take into account the non-hydrostatic pressure distribution in the curved sill region, an increment of grid points in the computational analysis was also performed in order to achieve an accurate numerical simulation. The increment of grid points along the flow direction in the region of the bottom sill gives a satisfactory comparison between numerical and experimental measurements and agreement is achieved. The 1-D hydrodynamic model simulation with the dense grid gives an accurate estimation of any abrupt free-surface flow variation. Water surface profile increases over the obstacle as inflow discharge increases and the abrupt water depth variation is presented for each hydraulic parameter. The expected abrupt decrease of flow depth at the downstream curved side of the rectangular sill is satisfactorily presented for each inflow discharge.

\section{Conclusions}

A laboratory experimental procedure was established to simulate free-surface variation over a river bottom sill, under steady flow conditions. All measurements were carried out in a laboratory, smooth open flume, and the test case geometry is formed from a rectangular shaped bottom sill. The main purpose is to produce a database on flow depth variation over a rectangular bottom sill in order to support fluid dynamic simulation models for computing free-surface flows in river control engineering works and protection against floods. 
The impact of abruptly altered open channel topography on the free-surface elevation was investigated under different inflow conditions. The range of water discharge was sufficient in order for new and existing codes to properly depict their capabilities against experimental results. The expected abrupt decrease of flow depth at the downstream curved side of the rectangular sill was adequately simulated with the experimental procedure, for each inflow discharge. Experimental water depth measurements reasonably simulated rapidly varied flow characteristics due to a sudden change in the geometry of the channel. Current laboratory measurements determine that flow was subcritical in the upstream face of the rectangular sill and supercritical in the downstream face of the sill. Moreover, a one-dimensional numerical simulation procedure of water surface profile variation over the rectangular bottom sill was performed and numerical results were satisfactorily compared with the experimental measurements and demonstrated the accuracy of the performed numerical simulation. All experimental data results are graphically presented and can be used by other numerical researchers to assist in the development of new and the verification and refinement of three dimensional, freesurface flow numerical simulation models, particularly those using non-hydrostatic pressure distribution.

\section{References}

Bahallamudi M, Chaudhry H (1992) Computation of flows in open channel transitions. J Hydraul Res 30:77-93 Bravo H, Zheng Y (2000) Turbulent flow over step with rounded edges: experimental and numerical study. J Hydraul Eng 126(1):82-85

Demetriou J, Retsinis E (2013) The length of a weak jump near a sill within inclined channel. J Emerg Technol Adv Eng 3(12):532-535

Farsirotou E, Soulis J, Dermissis V (2002) Comparison of 2-D and 1-D modeling of non-uniform flows in rivers. Proceedings of the International Conference on Protection and Restoration of the Environment VI, Vol. I: 311-317

Farsirotou E, Kotsopoulos S, Xafoulis N, Sanatsios G (2014) Experimental investigation of non-uniform flow in rivers. Proceedings of the $12^{\text {th }}$ International Conference on Protection and Restoration of the Environment, 873-880

Hamidifar H, Omid M (2011) Using a broad crested sill to control hydraulic jump in a triangular channel. J Civil Eng (IEB) 39(2):103-110

Liang J, Ghidaoui M, Deng J, Gray W (2007) A Boltzmann-based finite volume algorithm for surface water flows on cells of arbitrary shapes. J Hydraul Res 45(2):147-264

Meselhe E, Sotiropoulos F, Holly F (1997) Numerical simulation of transcritical flow in open channels. J Hydraul Eng 123(9):774-783

Ozmen-Cagatay H, Kocaman S (2011) Dam-break flow in the presence of obstacle: experiment and CFD simulation. J Eng Appl Comput Fluid Mech 5(4):541-552

US Army Corps of Engineers, Hydrologic Engineering Center (2010) HEC-RAS, River Analysis System, Version 4.1.0

Zerihum Y, Fenton J (2006) One-dimensional simulation model for steady transcritical free surface flows at short length transitions. Adv Water Resour 29:1598-1607 